\title{
Special issue on Tuta absoluta: recent advances in management methods against the background of an ongoing worldwide invasion
}

\author{
Antonio Biondi ${ }^{1} \cdot$ Nicolas Desneux ${ }^{2}$
}

Received: 8 May 2019 / Accepted: 10 June 2019 / Published online: 19 June 2019

c) Springer-Verlag GmbH Germany, part of Springer Nature 2019

Invasive arthropod pests hold great socio-economic and ecological importance, in the current global agricultural scenario (Paini et al. 2016). A recent estimate of the economic costs associated to invasive insects accounts to 70 billion US\$ per year globally, with associated health costs exceeding 6.9 billion US\$ per year (Bradshaw et al. 2016). In the past two centuries, the first records of invasive pests increased drastically, and about one-third of these happened in the past 40 years mostly likely due to the highly intensified human-mediated intercontinental exchanges (Seebens et al. 2017) and due to global warming (Bellard et al. 2013). In this context, Journal of Pest Science has focused most of its editorial efforts for attracting major contributions on the biology, ecology and possibilities of sustainable control of invasive pests. To this aim, various special article collections have been published on invasive insect pests, such as those attacking stored products (Athanassiou 2012) and forests and urban trees (Sweeney et al. 2019), the brown marmorated stink bug (Haye and Weber 2017), the spotted wing drosophila (Asplen et al. 2015; Biondi et al. 2016) and wireworms (Traugott et al. 2013).

This special issue aims at bringing together the most recent researches on the South American tomato pinworm, Tuta absoluta (Meyrick) (Lepidoptera: Gelechiidae) (Fig. 1). This moth is well known for causing drastic tomato yield losses owing to its leaf-mining activity and through occasional fruit infestation (Biondi et al. 2018; Desneux et al. 2010). Its ability to successfully develop on several crop and weed solanaceous species, as well as on non-solanaceous plants in lesser extent, makes its presence in tomato crops very challenging to avoid (Biondi et al. 2018; Campos et al.

Antonio Biondi

antonio.biondi@unict.it

1 Department of Agriculture, Food and Environment, University of Catania, Via Santa Sofia 100, 95123 Catania, Italy

2 INRA, CNRS, UMR ISA, Université Côte d'Azur, 06900 Nice, France
2017). In 2006, T. absoluta was detected in Spain, for the first time outside of its native range (South America). It rapidly spread across European and North African countries (Desneux et al. 2011) before colonizing most of the Asian (Han et al. 2019a) and African (Mansour et al. 2018) continents. Two major tomato-producing countries yet to be invaded, i.e. the USA (Tabuloc et al. 2019) and China (Xian et al. 2017), are currently threatened by the pest presence in the Caribbean (Verheggen and Fontus 2019) and in countries bordering China (Sankarganesh et al. 2017; Han et al. 2018), respectively. Its invasion in large cropping tomato areas resulted in large environmental and economic issues mainly linked with yield losses and widespread use of broadspectrum insecticides (Desneux et al. 2011). Following the T. absoluta arrival in European countries, various integrated pest management packages mainly based on monitoring, biological control and use of selective insecticides have been developed and implemented (Biondi et al. 2018).

We provided several original research articles reporting new findings on the biology and populations dynamics of $T$. absoluta, its chemical and trophic ecology, as well as a range of novel control tactics including molecular and biological control agents. Three review papers comprehensively covered the topics of T. absoluta insecticide resistance status and management (Guedes et al. 2019), the pest current status in the Asian continent (Han et al. 2019a), the implications for T. absoluta management of irrigation, fertilization and plant resistance (Han et al. 2019b), and Salas Gervassio et al. (2019) provided a comprehensive inventory of the available knowledge on T. absoluta parasitoids in its native area.

Finally, we wish to deeply thank all persons who made possible the publication of this special issue. We are thus grateful to all authors, to the qualified and volunteer reviewers and to the journal editor in chief, Michael Traugott. 


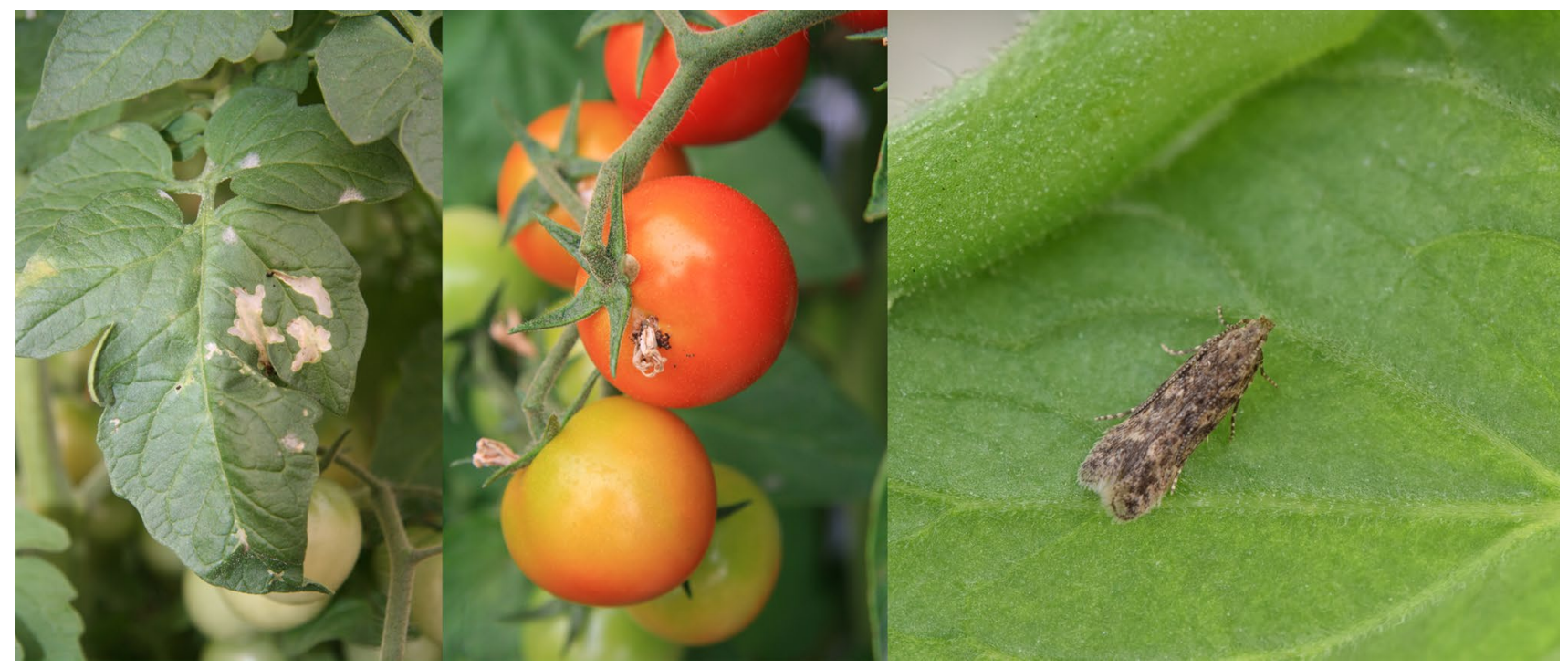

Fig. 1 Tomato leaflet with mines caused by Tuta absoluta larvae (left), tomato fruit infested by T. absoluta larvae (center), T. absoluta adult on tomato a leaf (right). Photograph credit: Antonio Biondi

\section{Compliance with ethical standards}

Conflict of interest The authors declare that they have no conflict of interest.

\section{References}

Asplen M, Anfora G, Biondi A, Choi D-S, Chu D et al (2015) Invasion biology of spotted wing drosophila (Drosophila suzukii): a global perspective and future priorities. J Pest Sci 88:469-494

Athanassiou CG (2012) Introduction to "Recent advances in stored product protection”. J Pest Sci 85:283-284

Bellard C, Thuiller W, Leroy B, Genovesi P et al (2013) Will climate change promote future invasions? Glob Change Biol 19:3740-3748

Biondi A, Traugott M, Desneux N (2016) The spotted wing Drosophila: from global invasion to sustainable control. J Pest Sci 89:603-604

Biondi A, Guedes RNC, Wan FH, Desneux N (2018) Ecology, Worldwide Spread and Management of the Invasive South American Tomato Pinworm, Tuta absoluta: past, present, and future. Annu Rev Entomol 63:239-258

Bradshaw CJ, Leroy B, Bellard C, Roiz D et al (2016) Massive yet grossly underestimated global costs of invasive insects. Nat Comm 7:12986

Campos MR, Biondi A, Adiga A, Guedes RNC, Desneux N (2017) From the Western Palaearctic region to beyond: Tuta absoluta 10 years after invading Europe. J Pest Sci 90(3):787-796

Desneux N, Wajnberg E, Wyckhuys KAG, Burgio G et al (2010) Biological invasion of European tomato crops by Tuta absoluta: ecology, geographic expansion and prospects for biological control. J Pest Sci 83:197-215

Desneux N, Luna MG, Guillemaud T, Urbaneja A (2011) The invasive South American tomato pinworm, Tuta absoluta, continues to spread in Afro-Eurasia and beyond: the new threat to tomato world production. J Pest Sci 84:403-408

Guedes RNC, Roditakis E, Campos MR, Haddi K, Bielza P et al (2019) Insecticide resistance in the tomato pinworm Tuta absoluta: patterns, spread, mechanisms, management and outlook. J Pest Sci. https://doi.org/10.1007/s10340-019-01086-9

Han P, Zhang YN, Lu ZZ, Wang S et al (2018) Are we ready for the invasion of Tuta absoluta? Unanswered key questions for elaborating an Integrated Pest Management package in Xinjiang, China. Entomol Gen 38:113-125

Han P, Bayram Y, Shaltiel-Harpaz L, Sohrabi F, et al (2019a) Tuta absoluta continues to disperse in Asia: damage, ongoing management and future challenges. J Pest Sci https://doi. org/10.1007/s10340-018-1062-1

Han P, Desneux N, Becker C, Larbat R et al (2019b) Bottom-up effects of irrigation, fertilization and plant resistance on Tuta absoluta: implications for Integrated Pest Management. J Pest Sci. https://doi.org/10.1007/s10340-018-1066-x

Haye T, Weber DC (2017) Special issue on the brown marmorated stink bug, Halyomorpha halys: an emerging pest of global concern. J Pest Sci 90:987-988

Mansour R, Brévault T, Chailleux A, Cherif A, Grissa-Lebdi K et al (2018) Occurrence, biology, natural enemies and management Tuta absoluta in Africa. Entomol Gen 38:83-111

Paini DR, Sheppard AW, Cook DC, De Barro PJ et al (2016) Global threat to agriculture from invasive species. Proc Natl Acad Sci USA 113:7575-7579

Salas Gervassio NG, Aquino D, Vallina C, Biondi A, Luna MG (2019) A re-examination of Tuta absoluta parasitoids in South America for optimized biological control. J Pest Sci. https://doi. org/10.1007/s10340-018-01078-1

Sankarganesh E, Firake DM, Sharma B et al (2017) Invasion of the South American Tomato Pinworm, Tuta absoluta, in northeastern India: a new challenge and biosecurity concerns. Entomol Gen 36:335-345

Seebens H, Blackburn TM, Dyer EE, Genovesi P et al (2017) No saturation in the accumulation of alien species worldwide. Nat Comm 8:14435 
Sweeney J, Rassati D, Meurisse N, Hurley B, Duan J, Stauffer C, Battisti A (2019) Special issue on invasive pests of forests and urban trees: pathways, early detection, and management. J Pest Sci 92:1-2

Tabuloc CA, Lewald KM, Conner WR, Lee Y et al (2019) Sequencing of Tuta absoluta genome to develop SNP genotyping assays for species identification. J Pest Sci 1:1. https://doi.org/10.1007/ s10340-019-01116-6

Traugott M, Schallhart N, Staudacher K, Wallinger C (2013) Understanding the ecology of wireworms and improving their control: a special issue. J Pest Sci 86:1-2
Verheggen F, Fontus B (2019) First record of Tuta absoluta in Haiti. Entomol Gen 38:349-353

Xian XQ, Han P, Wang S, Zhang G et al (2017) The potential invasion risk and preventive measures against the tomato leafminer Tuta absoluta in China. Entomol Gen 36:319-333

Publisher's Note Springer Nature remains neutral with regard to jurisdictional claims in published maps and institutional affiliations. 